\title{
Quality EContent Design using Reusability approach
}

\author{
Senthil Kumar.J, \\ (Research Scholar, Vels University, India.) Asst. \\ Professor, Dhanraj Baid Jain College, India
}

\author{
Dr S.K.Srivatsa, Ph.D., \\ Professor, St.Josephs College of Engg. , India
}

\begin{abstract}
Technology is the one changing ever, and major technological innovations can make a paradigm shifts. The computer network known as the Internet is one such innovation. After affecting sweeping changes in the way people communicate and do business, the Internet is perched to bring about a paradigm shift in the way people learn. Consequently, a major change may also be coming in the way educational materials are designed, developed, and delivered to the learner. An instructional technology called "learning objects" currently leads other candidates for the position of technology of choice in the next generation of instructional design, development, and delivery. This paper aims to address the reusability, generating capability, adaptability, and scalability of the content designed using the learning objects. Object-orientation highly values the creation of components (called "objects") that can be reused in multiple contexts. This is the fundamental idea behind learning objects.
\end{abstract}

Keywords- Technology; paradigm; network; learning objects.

\section{INTRODUCTION}

The instructional technology communities have begun to grapple with mapping sound instructional principles to the technical attributes of learning object systems for education and training purposes [1]

Learning object systems are flexible, dynamic and highly engaging technology-based environments. These systems have great potential to capitalize on the goal-oriented nature of human learning processes as well as allowing learners to associate instructional content with their prior knowledge and individual experiences

The transition of the education and training communities to paperless, digital work and learning environments has important implications. They often involve the re-production of media and approaches that have been developed. Previously, tending to increase dramatically both the cost and the time required to develop training and education products and services. Simply re-hosting existing education and training approaches using digital media may optimize neither human nor technology's capabilities.

\section{InStructional Design Based on Object ORIENTED APPROACH-PEDAGOGICAL SHIFT}

Before the industrial revolution, a craft based approach to product manufacture was prevalent, where one or two individuals create a completed product form the raw material available to them. After the industrial revaluation there were many changes in product manufacturing. The major developments were the division of labor, increased automation and to development of the component based approach to manufacturing. The main benefit of a component based approach is reusability is a component used on product can be used to provide the same function for another product. Parallel to the industrial revolution has occurred within a shorter time frame in the software industry. It is only since the development of the idea of software engineering in the 1970's that software development has begun to move from a craft to an industry.

The Idea of moving to a component model for development of courses and content has gained prominence move recently and been driven by the interest in the educational potential of the internet. There are number of initiatives which transfer the ideas and benefits of the component approach to developments and delivery of educational systems [2].

A learning component more commonly referred as a learning object is any discrete unit of learning material that can be extracted from one course and integrated into another.

Reusable learning object is an emerging paradigm shift in instructional system that promises to bring to education the same improvements in productivity that it has in software development. There are number of problems to be resolved before component manufactures becomes an established approach in educational system design. These include the issues of standards for learning objects and support for those educators making the transition to object based design.

\section{OBJECT ORIENTED APPROACH FOR CREATING REUSABLE AND TRANSPORTABLE LEARNING CONTENT}

a) Transportable among applications and environments

b) Re-purposable to different delivery structures.

To be reusable and transportable an object needs to meet some technical coding standards and it must be instructionally designed for reuse. In addition each learning object must be labeled to make identification of content, topic, purpose, etc. readily apparent and to make the object easily retrievable. There are "two requisite components of a learning object: the object content and its metadata tag." [3] Meta-tagging means linking or tagging objects and assets with specific metadata. "Metadata, literally 'data about data', is descriptive information about a resource...metadata allow you to locate an item very quickly without investigating all the individual items through which you are searching."'[4] Because they are stored in a database structure and managed through a Learning Content Management System via meta-tagging, learning objects make it easy to find and access content anywhere and anytime and they are easy to update and display. 


\section{FEATURES OF LEARNING OBJECTS}

The following is a list of some of the types of information that may be included in a learning object and its metadata:

- General Course Descriptive Data, including: course identifiers, language of content (English, Spanish, etc.), subject area (Moths, Reading, etc.), descriptive text, descriptive keywords

- Life Cycle, including: version, status

- Instructional Content, including: text, web pages, images, sound, video

- Glossary of Terms, including: terms, definition, acronyms

- Quizzes and Assessments, including: questions, answers

- Relationships to Other Courses, including prerequisite courses

- Educational Level, including: grade level, age range, typical learning time, and difficulty.

\section{Metadata Standards FOr Learning ObJECts}

Learning objects are indeed a good idea, but as long as they lack instructional value, we will be unable to use them effectively. From a practical and technical perspective, common metadata standards define what data needs to be collected and stored to provide descriptive information about a content object. The result is a content object metadata specification (e.g., showing title, author, and description for each object). Metadata standards theoretically should also enable the appropriate use of a content object as a learning object. In this case, the purpose is to enable learners to use one or more learning objects to achieve one or more instructional objectives.

The metadata on a library catalog card provides information commonly used for finding a book or other media form, but has little instructional information concerning the reader's instructional use of the item. If our sole purpose is to provide metadata for describing content objects, the descriptive information commonly included by most standards today is sufficient. However, learning objects have important embedded instructional objectives and, if we are not providing instructional information in metadata, all we have is a content object. If we ignore key instructional issues, how can we successfully use learning objects for learning?

Many groups are working together to define common international standards that the world can adopt for describing learning objects that can be interoperable, reusable, repurposable, and effectively managed and presented. Their common interest is to find a minimum set of metadata standards that will support the worldwide deployment of learning objects for multiple purposes. Just a few of the groups participating in these worldwide standards-making efforts through the IEEE Learning Technology Standards Committee [5] are:

- Alliance of Remote Instructional Authoring and Distribution Networks for Europe (ARIADNE, 2000)

- Instructional Management Systems (IMS, 2000a) Project

- Dublin Core Education Working Group (DC-Ed, 2000)

- Advanced Distributed Learning Initiative (ADL, 2000)

\section{Mutabilitgy OF LEARNING OBJECT}

A mutated learning object is, according to Michael Shaw, a learning object that has been "re-purposed and/or reengineered, changed or simply re-used in some way different from its original intended design". Shaw also introduces the term "contextual learning object", to describe a learning object that has been "designed to have specific meaning and purpose to an intended learner". [6]

\section{PORTABILITy OF LEARNING OBJECT}

Before any institution invests a great deal of time and energy into building high-quality e-learning content (which can cost over $\$ 10,000$ per classroom hour), it needs to consider how this content can be easily loaded into a Learning Management System. It is possible for example, to package learning objects with SCORM specification and load it at Moodle Learning Management System. If all of the properties of a course can be precisely defined in a common format, the content can be serialized into a standard format such as XML and loaded into other systems. When you consider that some e-learning course need to include video mathematical equations using MathML, chemistry equations using CML and other complex structures the issues become very complex, especially if the systems needs to understand and validate each structure and then place it correctly in a database.

\section{LEARNING OBJECT PROJECTS}

Some examples of learning object projects include:

- AGORA, a publicly accessible online learning environment at the Virtual Museum of Canada. Content is created and produced by Canadian museum educators.

- eduSource, a Canada-wide project to create the infrastructure for a network of inter-operable learning object repositories. The eduSource project is based on national and international standards; it is bilingual (French and English) and designed to be fully accessible.

- MERLOT (Multimedia Educational Resource for Learning and Online Teaching), a free and open resource designed primarily for faculty and students of higher education.

- IQity Reactor is a learning object repository that allows educators to create and share custom curriculum, organized by state educational standards. Reactor is integrated with a learning management system.

- Wisc-Online is a web-based repository of learning objects, developed primarily by faculty members from the Wisconsin Technical College System.

\section{CONCLUSION}

Object-orientation highly values the creation of components (called "objects") that can be reused in multiple contexts. This is the fundamental idea behind learning objects. Instructional designers can build small instructional components that can be reused a number of times in different learning contexts. Additionally, learning objects are generally understood to be digital entities deliverable over the Internet, meaning that any number of people can access and use them simultaneously. 
Moreover, those who incorporate learning objects can collaborate on and benefit immediately from new versions. These are significant differences between learning objects and other instructional media that have existed previously.

\section{REFERENCES}

[1] Merrill, M. D. (1999a). Instructional transaction theory (ITT): Instructional design based on knowledge objects. In C. M. Reigeluth (Ed.), Instructional-Design Theories and Models:

[2] Roschelle, J., Kaput, J. Stroup, W. and Kahn, T.M.., "Scalable integration of educational software: exploring the promise of component architectures: Journal of Interactive media in education, volume 6, 1998, www-jime.open.ac.uk/98/6

[3] Longmire, Warren. (2000). A Primer on Learning Objects.

[4] Wiley David A (2000).Connecting learning objects to Instructional Design Theory

[5] Learning Technology Standards Committee (2002) (PDF), Draft Standard for Learning Object Metadata. IEEE Standard 1484.12.1, New York: Institute of Electrical and Electronics Engineers, retrieved 20080429

[6] http://www.shawmultimedia.com/edtech_oct_03.html. 